\title{
National courses in online retrieval in the Netherlands
}

\author{
K. van der Meer, L.M. Koster and D.L. Brand-de Heer
}

The advent of online information systems has been followed by gradual improvements in both their accessibility and ease of operation. This and the low cost of machine-searching, certainly compared with manual searching, are factors which have persuaded many organisations to use such systems. Consequently, a growing number of staff are required to operate them and, as a result, a steady demand for online training courses has been established.

Prior to 1977, no organisation existed in the Netherlands that was capable of giving such courses. However, in that year, VOGIN, the Online User Group in the Netherlands, was formed and, like many other national online user groups, recognised the field of online education as one to which it could contribute in a major way. Within the VOGIN framework, individuals with parallel ideas on online education met, and subsequently the VOGIN Working Group for Education and Training was set up.

With the necessary self-confidence and much enthusiasm, this Working Group organised the first VOGIN course, assisted by 'GO', the Netherlands' Institute of Record Management, Library, Documentation and Information Science. This course took place in 1978 and was probably the world's first training course arranged and given by a user group. The Ministry of Science Policy reacted quickly and favourably to a request for a guarantee subsidy of Dfl 5000 , to which an

K. van der Meer is Deputy Librarian at Delft University of Technology, Doelenstraat 101, Delft I, Postbus 98, The Netherlands. L.M. Koster is an information scientist at PUDOC. D.L. Brand- de Heer is with the Directorate-General of Labour at the Netherlands Ministry of Social Affairs. appeal could be made, if required by the financial position.

This first course was a success for both organisers and participants. The demand for such a course has continued and it has therefore been repeated several times now. Minor changes in content have occurred and COBIDOC, the Commission for Bibliography and Documentation, has taken over the administrative function from GO.

\section{Layout of the course}

An outline of the contents of the course is given in the tables.

Table 1. Lectures on the first day of the course.

The prospects of online searching

Online databases and systems

The searching process

Use of online searching possibilities

Table 2. Lectures and subsequent practical training sessions on days 2 to 5 of the course.

Fundamental commands

Essential technical knowlèdge*

Development of search strategies

Comparison of databases

Comparison of hosts

Comparison of search strategies

Evaluation of output

Comparison of costs and benefits*

*No practical training session. 
The aim of the full five-day course is to provide fundamental knowledge in all aspects of online and to give experience in online information retrieval. For a brief introduction to online, it is also possible to attend the first day only, which includes no practical training. This is considered useful for directors, managers and the like, who require or desire a background knowledge of online systems, but who do not have to deal directly with their use.

As it is a general course, no specific host or database is privileged. Hands-on training is possible using the hosts LIS, SDC, IRS (ESA), FIZ, DIMDI, and IAEA. The learning of several command languages can cause confusion (for example, stop on Dialog does not result in being logged off, but gives a good yield on top), and the various dialects of the Common Command Lanaguage are annoying, but the possibilities and options of online searching are demonstrated and remain clear. The ten lecturers are experienced online searchers from all over the Netherlands, none of them being associated with a particular database, host or telecommunication organisation.

The number of participants in the full course is limited to 24 , this being the number of terminals available for the practical sessions. There are seven independent terminals so that the participants can work in groups of three or four.

During the practical sessions, the course supervisor, the lecturer and assistants give guidance to the seven groups at the terminals. Most participants' reactions would lead one to believe that a terminal has as much playing value as a pinball machine. However, to those newly introduced to the online "phenomenon', a terminal not responding in the appropriate way can be a particularly nasty thing. Even though one should not interfere with every participant's struggle at the terminal, supervision must be close at hand, and therefore one assistant can only adequately deal with two or three groups.

The price of the full course is Dfl 675 $(\$ 310)$, including lunches and the course book, and that of the one-day course Dfl 100
(\$45), including lunch. Approximately 30\% of this is actual online costs, kept low thanks to hosts providing reduced and/or free passwords and due to the low Euronet tariff. The prices prove to be correctly fixed; they balance the expenditure and it has not been necessary to draw on the guarantee subsidy.

\section{Sovin}

The first and second courses were held in the Leeuwenhorst Congress Centre in Noordwijkerhout. It took some arranging to obtain seven terminals and telephone lines, not to mention a VDU, monitors and all kinds of manuals. Then came the frightful task of connecting everything correctly, followed by the efforts associated with attempting to keep all terminals permanently 'in the air'. Despite the assistance of the technical staff of the Leeuwenhorst, the problems were sufficient for us to declare this location not totally suited to our purpose.

The course moved to the newly founded SOVIN online training centre at the earliest opportunity. SOVIN is a non-profit foundation whose major task is the exploitation of this training centre. Some ten organisations participate in SOVIN, most of them governmental bodies with some link with either the development or education of information work. The Netherlands' Ministry of Education and Science is one of the participants and is represented by COBIDOC. GO and VOGIN are also participants.

The SOVIN online training facility is in Utrecht, one of the most central places in the Netherlands and well situated as regards access by train from all parts of the country. The centre is permanently equipped with seven terminals and telephone lines, four monitors, various equipment for demonstration purposes, plus a wealth of manuals and other searching guides. Up to 30 people can be accommodated and the catering facilities are commendable. The centre is available to Netherlands' or foreign organisations on a perday basis, the hire fee being approximately Dfl $700(\$ 325)$ per day, depending on the equipment required. Indeed, this price draws 
heavily on the course budget, but VOGIN is very pleased with SOVIN, and its advantages are such that a move elsewhere is not considered.

\section{After five courses}

The VOGIN courses have become wellestablished in the Netherlands and will be repeated periodically. As yet the lecturers have not objected to the lecturing frequency and up until now, far more subscriptions have been received every time than the maximum 24. The fact that the course is given in Dutch and its generality prove to be valuable features.

Online terminals are becoming increasingly common in libraries and documentation centres so that one might expect current participants to know more about online than earlier ones. However, this is not so, more participants having less knowledge of online nowadays than their predecessors. An explanation of this trend probably lies in the explosive growth in the use of online. In the Netherlands, 14,000 searches were performed in one or more databases during 1978 ; in 1981 this figure is expected to reach 50,000 . Consequently far more people are becoming involved with this work and nowadays they are often recruited from the scientific world rather than the library and information world, where online has yet to penetrate fully.

Within the library, staff are also coming into contact with online systems via other activities such as the automation of collections, interlibrary loans, etc. For these groups a one-day introductory course without handson training is too limited and a one-day succession to the first day is being developed which will include practical sessions. It is not expected that this will drastically reduce interest in the full course.

As a fundamental guide, J. L. Hall's book, On-Line Information Retrieval Sourcebook, used to be recommended as a supplement to the course. However, the lecturers have recently developed a Dutch language course book which has been published, and a copy of this is now included in the course fee.

The VOGIN courses are alive, well and kicking. They are expected to continue for quite some time to come. 